\title{
Educação e formação em dança: A inserção da expressão criativa nos cursos técnicos de dança na perspectiva de professores e bailarinos
}

Priscila Trevisan', Gisele Schwartzii, Nara Rodriguesiii \& Ana Paula Teodoroiv

Universidade Estadual Paulista, Brasil

Resumo

Este estudo qualitativo investigou como a expressão criativa é inserida no processo de ensino e aprendizagem dos cursos técnicos de formação em dança, na visão de bailarinos e professores. Este estudo exploratório foi desenvolvido por meio de questionário aberto, aplicado a uma amostra intencional composta por 10 professores e 10 bailarinas de cursos técnicos de formação em dança de Pirassununga-SP-Brasil. Os dados foram analisados descritivamente, por meio da Técnica de Análise de Conteúdo. Os resultados indicam que, conquanto a expressão criativa seja amplamente percebida como relevante na apropriação das individualidades para o fazer artístico e seja enfatizada no trabalho didático-pedagógico, sua inserção é minimizada no contexto educativo da dança, em contraposição à valorização dada aos aspectos técnicos. O seu desenvolvimento é permeado por aspectos subjetivos no decorrer das aulas e se apresenta de forma esparsa. Outros estudos são necessários para redimensionar e revitalizar esta temática em âmbito acadêmico.

Palavras-chave

Dança; Criatividade; Formação profissional; Educação 


\section{Introdução}

A compreensão sobre o desenvolvimento da criatividade por meio da arte-educação já tem sido foco de alguns estudos académicos (Bastos \& Zimmerman, 2015; Zimmerman, 2013). Entretanto, para que se possam compreender todos os prismas de abrangência dessa relação, são necessários esforços capazes de elucidar as lacunas ainda existentes, dada a complexidade das dinâmicas que envolvem os termos - criatividade, arte e educação. Ao se restringir o olhar para o âmbito dos cursos de formação em dança, esta complexidade se intensifica. Apresenta-se como um desafio buscar compreender o modo como a expressão criativa é apreendida no contexto dos cursos de formação técnica em dança, uma vez que esta formação fornece uma das bases responsáveis por inserir esse profissional em um mercado de trabalho que requer o uso desse potencial criativo.

A iniciação nos cursos de dança acontece, na maior parte das vezes, na infância e perdura na adolescência ou até na vida adulta, promovendo uma extensa gama de experiências relevantes para uma discussão acerca desse contexto social. Muitas escolas de dança possuem seus cursos reconhecidos pelo Ministério da Educação e Cultura (MEC) no Brasil, no âmbito da formação técnico-profissional, como é o caso dos cursos selecionados para esse estudo.

Essa formação técnica se refere a um nível da Educação Profissional, a qual tem como objetivos, além da formação de técnicos, a qualificação e o permanente desenvolvimento de aptidões para as atividades da vida produtiva, social e profissional (Decreto Lei 5.154/2004, 2004). O técnico em dança deve, entre outros, dominar diferentes estilos de dança e empregar técnicas específicas, bem como recursos que conduzam a atuações que requerem o exercício da criatividade para o domínio artístico na dança. Além de atuar como bailarino, diretor, assistente de palco ou contrarregra, o técnico em dança pode desenvolver atividades ligadas à criação e execução da dança em espaços alternativos para o lazer, cultura e produção artística, como espetáculos, festivais e mostras, que ocorrem nos vários espaços cênicos propícios para sua atuação (Ministério da Educação, 2014). Sendo assim, o desenvolvimento de qualidades como a criatividade, nesse contexto educativo, pode trazer perspectivas de grande valor. 


\section{Enquadramento teórico}

Alguns estudos, como os de Winner, Goldstein, e Vincent-Lancrin (2014) salientam a arte-educação como um importante meio de engendrar a criatividade. Autores como Hetland, Winner, Veenema, e Sheridan (2013) ressaltam que, em todos os tipos de arte, as aulas devem ser voltadas para treinar os estudantes a serem mais criativos no domínio de suas habilidades artísticas. Assim, professores devem incentivar seus alunos a explorarem diferentes situações, assumirem riscos, experimentarem e tentarem coisas novas.

Especificamente em dança, Brown (2015) destaca os desafios referentes a como os programas de dança-educação podem permitir a individualidade, a criatividade, a imaginação e a curiosidade. A autora reconhece a rica herança dessa arte para a expressão individual, para a promoção da aprendizagem e para se engendrar a sensibilidade. Mais do que aprender uma rotina de passos de dança executados com proficiência técnica, muitos dança-educadores estão preocupados em desvelar como a dança pode educar fisicamente, socialmente, emocionalmente e intelectualmente. Assim, as propostas e estratégias pedagógicas devem encorajar o investimento no aprender a lidar com a criatividade e, para tanto, devem utilizar diferentes recursos, considerando o foco no educar para o século XXI.

Por ser a dança uma linguagem permeada por uma intencionalidade expressiva, em que o ser humano utiliza seu corpo para realizar essa arte, de acordo com Marques, Surdi, Grunennvaldt, e Kunz (2013), a formação em dança deve compreender, não apenas a aquisição de técnicas, mas, sobretudo, transformar as ações corporais e o fazer da dança em manifestações capazes de aflorar a imaginação, a espontaneidade, o senso crítico.

A formação de profissionais capazes de atuarem, por meio da linguagem dança, na construção de um meio significativo de arte e expressão, e de promoverem o exercício da criatividade se torna um foco importante para essa atuação. Entretanto, evidencia-se a escassez de estudos que promovam reflexões acerca da apropriação da expressão criativa no contexto dos cursos técnicos de formação em dança, o que justifica o interesse deste estudo. 
Dessa forma, torna-se premente um olhar crítico, também por parte do meio académico, tanto para o teor dos conteúdos desenvolvidos nos cursos técnicos de dança, como para a dimensão em que a criatividade é apreendida pelos envolvidos nesse processo formativo. Sendo assim, este estudo teve por objetivo investigar como a expressão criativa é inserida no contexto de ensino-aprendizagem nos cursos técnicos de formação em dança, na visão de professores e de bailarinas.

No que se refere à definição, parece existir uma concordância entre pesquisadores e educadores de que criatividade envolve um complexo processo, no qual fatores relacionados à pessoa, processo, produtos e contextos socioculturais estão inter-relacionados (Sternberg \& Lubart,1999; Sternberg, 2012). Desta maneira, diferentes estudos se dirigem à análise das características dos indivíduos e produtos tidos como criativos, e a como e por meio de quais processos acontece a avaliação do que passa a ser designado como criativo.

Desta forma, pesquisadores consentem uma visão multidimensional, a qual requer a confluência de habilidades, conhecimentos, estilos de pensar, personalidade e ambiente (Lubart, 2007). Para Csikszentmihalyi (2013), a criatividade é definida por um ato, ideia ou produto que modifica um domínio existente, ou transforma esse em um novo. Segundo o autor, esse fenómeno é construído a partir da interação entre indivíduo, diferentes domínios e campos. O domínio representa um conjunto de regras e procedimentos e faz parte da cultura; o campo abrange o sistema social em que o indivíduo está inserido; e o indivíduo é aquele a quem cabe a tomada de decisão e a introdução de mudanças.

Em Csikszentmihalyi e Wolfe (2014), criatividade é definida como uma idéia ou produto original e de valor. Para esses autores, a originalidade se refere a algo novo e valioso. Criar consiste em quebrar paradigmas conceituais para resolução de problemas em meio a um processo inseparável de conquistas sociais e culturais anteriores.

O termo criatividade, além de associado à resolução de problemas, engloba a capacidade de gerar um amplo leque de ideias (fluência), de se adaptar a novas maneiras de pensar (flexibilidade) e dar respostas, não usuais (originalidade), o que sugere a capacidade de interpretar e mudar a estratégia de se fazer uma tarefa (Zimmerman, 2013). 
$\mathrm{Na}$ arte, a expressão da criatividade é um processo relativamente subjetivo. Zimmerman (2013) destaca que, na arte-educação, a criatividade pode ser descrita como um estilo de pensar, em que a adaptação às mudanças inclui as dimensões da expressão referentes a representar, traduzir, integrar e sintetizar, ou seja, uma forma de transformar em novo, não apenas materiais e produtos, mas também o próprio indivíduo criador. De forma crítica, isto pode significar ir além da geração de novos conceitos, mas também expandir os convencionais. Ainda, a autora salienta que, na arteeducação, a criatividade deve ser focalizada nas teorias educacionais, de forma a que a expressão criativa e a resolução de problemas sejam incluídas no desenvolvimento de habilidades para a aprendizagem. Deste modo, a habilidade desenvolvida é um prelúdio necessário para a criativa interação entre o indivíduo e o domínio da arte. Zimmerman (2013) salienta igualmente que, em um contexto educativo, em sala de aula, a criatividade precisa ser considerada em um processo integrado entre professores, estudantes, currículo e ambiente.

Para Bastos e Zimmerman (2015), a criatividade na arte-educação deve ser considerada não somente como expressão criativa individual, mas também ser enfatizada com base no desenvolvimento de uma identidade cultural, nas tecnologias e nas realidades existentes. De acordo com Sawyer (2012), a criatividade na arte segue a lógica dos estilos e técnicas, da organização social, das funções sociais. Assim, um produto, um gesto, um movimento, no caso da dança, só será considerado criativo se for reconhecido por seu valor sociocultural.

No decorrer de sua evolução sociocultural, a dança remonta uma gama de opções e representações, no que se refere ao desenvolvimento dos diferentes estilos e às formas de expressão. Em meio às diferentes formas de manifestações artísticas e populares, foram se delineando e construindo demandas inovadoras, que visavam decifrar a linguagem corporal por meio da arte, podendo salientar-se que o percurso histórico da dança alavancou um reconhecimento de que a expressão criativa dá suporte tanto para o ato de dançar como aos processos formativos e educativos.

Já no século XX, a dança é reconhecida como uma forma de expressão e apreensão dos sentimentos; dessa forma, tornou-se premente ampliar os padrões de movimento existentes, visando tornar a dança mais 
expressiva e significativa àqueles que se apropriavam dessa forma de arte. Assim, Lopes (2009) destaca que, na perspectiva de se atingir esses novos objetivos, passou a ser evidenciado o princípio de que dançar era algo essencialmente ligado às emoções e deveria acontecer de forma mais livre. Nesse contexto, surgem ícones como Isadora Duncan, Martha Graham, entre outros, os quais obtiveram notável destaque no universo da dança.

Rudolf Laban e Isadora Duncan foram precursores de base até hoje essenciais para a análise do movimento e correspondência harmoniosa entre suas qualidades expressivas, recebendo, portanto, atualmente, muito destaque, não só na dança, mas em diferentes esferas da arte-educação. Para Medina, Ruiz, Almeida, Yamaguchi, e Marchi Jr. (2008), na dança, as dinâmicas propostas por Laban permitem ao bailarino organizar e diversificar seus movimentos corporais em diferentes planos, por meio de uma variedade de ações, entre fatores de movimento que se inter-relacionam, como fluência, espaço, tempo e intensidade. Assim, na dança, o bailarino, com seu corpo, utiliza o espaço de acordo com um ritmo, um tempo estabelecido para cada mudança de ação, e se expressa estabelecendo intensidades, dentro de uma fluência que controla e orienta seus movimentos corporais.

Tomando por base as concepções de que criatividade envolve flexibilidade, fluência e originalidade e de que a dança envolve necessariamente o movimento corporal de acordo com o ritmo e o tempo propostos, podem-se destacar os apontamentos feitos por Zachopoulou e Makri (2005), referindo que, associada ao movimento, a criatividade implica no envolvimento motor dos aspectos anteriormente citados. Para esses autores, a fluência motora se refere ao número de respostas dadas por meio do movimento, a flexibilidade motora ao número de mudanças temáticas, e a originalidade à singularidade da resposta, ou seja, do movimento, em relação ao que se tem como modelo. Ainda para esses autores, a habilidade para o movimento divergente, isto é, para modificar e produzir diferentes padrões nos movimentos fundamentais durante as atividades desenvolvidas, inclui a criatividade motora, o que significa combinar fluência e flexibilidade nos movimentos, por meio do pensamento crítico. A criatividade motora, para Wyrick (1968), pode ser definida como a combinação de percepções por meio de novos padrões, os quais podem ser tanto uma solução para um problema pré-estabelecido, como a expressão de uma ideia ou uma emoção por meio de corpo. 
Assim, a criatividade na dança pode ser expressa por meio da habilidade de produzir a imaginação, por intermédio de posições e movimentos, de acordo com ritmos e com a habilidade do bailarino, de forma a re-ordenar, adicionar e gerar uma variedade de movimentos, de acordo com o contexto solicitado. Para Vygotski (2009), a imaginação é a base da criatividade, sendo que os processos de criação na arte são produtos extraídos da combinação entre a realidade e a imaginação, os quais são recriados e reorganizados por novas maneiras e abordagens. A arte, para esse autor, é a técnica social dos sentimentos, a qual depende da interação entre o que o indivíduo percebe e sua imaginação e envolve o emocional.

Nesse sentido, na dança, a capacidade expressiva apresenta grande importância. O termo expressão, não raro, pode representar uma linguagem e, neste sentido, estar provida de sentidos e significados (Marques, 2012). Quando envolvida na dança, a expressão criativa se refere a ações ou gestos que são manifestados e que podem envolver as emoções, assim como detalhes das individualidades e intencionalidades dos gestos da pessoa que dança.

Dessa forma, para esse estudo, a expressão criativa pode ser tomada como uma forma de criação, em que o ato de dançar é aliado a uma forma de expressão. $O$ indivíduo demonstra sua criatividade por meio da manifestação de gestos e movimentos, reconstruídos com base no que é novo e significativo para os contextos, tanto individuais e emocionais, como sociais. Assim, a expressão da criatividade tem lugar quando o fazer e o saber da dança são utilizados como um domínio capaz de desenvolver uma nova ideia, por meio de ações corporais diferenciadas, em que os gestos do indivíduo que dança são reconhecidos, por suas qualidades, intencionalidades e significados, como uma novidade, a qual é selecionada, incluída e aceita como adequada ao contexto proposto. No entanto, ao se focalizar a manifestação artística referente à dança, nem sempre esses potenciais criativos são enfatizados ou valorizados (Piccinini \& Saraiva, 2012).

Conquanto a literatura já evidencie a importância de um ambiente educacional permeado pelo incentivo e valorização do desenvolvimento da expressão criativa, pode ser percebido que o processo ensino-aprendizagem da dança encontra-se atravessado por questões que ainda precisam ser redimensionadas. Nessa perspectiva, pode-se destacar a escassez de 
estudos, por parte do meio acadêmico, para se avaliar a extensão e as formas com que a expressão criativa tem sido estimulada ou inserida no contexto dos cursos de formação técnica em dança, o que representou o mote da pesquisa exploratória descrita a seguir.

\section{Método}

Este estudo, de natureza qualitativa, teve por objetivo investigar como a expressão criativa é inserida no processo ensino-aprendizagem dos cursos técnicos de formação em dança, na visão de bailarinos e professores de dança da cidade de Pirassununga-SP-Brasil. Para tanto, foi realizada uma pesquisa bibliográfica acerca da temática, aliada a uma pesquisa exploratória.

O instrumento utilizado para a coleta dos dados foi um questionário aberto, sendo um elaborado especificamente para os professores e outro para as bailarinas. Esse questionário visou tanto a caracterização da amostra quanto à idade, sexo e tempo de prática, como obter a perspectiva dos sujeitos a respeito de como acontece a inserção da expressão criativa como um conteúdo desenvolvido nos cursos técnicos analisados, com base nas questões abertas seguidamente apresentadas.

Para os professores: 1) Para você, o que significa expressão criativa na dança?; 2) Quando ensina a dança, o que procura enfatizar/ressaltar ao aluno?; 3) Em suas aulas, você inclui atividades para desenvolver a expressão criativa nos alunos? Quais?. Para as bailarinas: 1) Para você, o que significa expressar-se criativamente na dança?; 2) Quando aprende a dançar, o que é enfatizado/ressaltado pelo professor?; 3) Durante as suas sessões/aulas de dança, são propostas atividades para desenvolver a expressão criativa? Quais?; 4) Em que momento você percebe com mais facilidade esta expressão criativa?

A amostra intencional de 20 sujeitos, maiores de 18 anos, foi composta por 10 professores e 10 bailarinos. Os professores apresentaram idades que variaram entre 23 e 58 anos, sendo 7 do sexo feminino e 3 do sexo masculino. O tempo de prática com a atividade de dança entre esses profissionais variou de 5 a 30 anos. No que se refere aos outros 10 participantes, bailarinos, todos eram do sexo feminino e estudantes de um mesmo curso técnico de dança da cidade de Pirassununga/SP-Brasil, com faixa etária de 18 a 25 anos. Entre as bailarinas, o tempo de prática com a dança variou de 8 a 14 anos. 


\section{Procedimento}

Este estudo foi aprovado pelo Comitê de Ética em Pesquisa, do Instituto de Biociências, UNESP, Campus Rio Claro/SP-Brasil, sob o protocolo $n^{\circ} 1523$. As questões pertinentes ao instrumento foram elaboradas de acordo com a análise de três especialistas da área, portadores de título de doutor, os quais julgaram a adequação das mesmas para se atingir o objetivo proposto.

Os dados foram coletados em duas escolas que possuíam seus cursos técnicos de dança oficializados e reconhecidos pelo MEC. Esses cursos foram escolhidos por serem tradicionais na cidade de Pirassununga há mais de 40 anos. Cabe salientar que as 10 bailarinas eram alunas dos professores que participaram desse estudo, ambos (docentes e alunas) dos referidos cursos.

Inicialmente, foi feito um contato prévio com os sujeitos, visando esclarecer os objetivos do estudo e detalhes éticos relativos ao desenvolvimento da pesquisa. Em seguida, foi feito o convite para participarem da amostra, ressaltando as garantias de anonimato das respostas, da possibilidade de interrupção a qualquer momento e dos procedimentos éticos de pesquisa com seres humanos. De posse da anuência dos sujeitos, o questionário foi entregue aos participantes, que responderam individualmente, visando assim oferecer-lhes maior liberdade de expressão.

Para a análise descritiva dos dados foi utilizada a Técnica de Análise de Conteúdo proposta por Bardin (2011), a qual se caracteriza pela utilização de temas representativos dos itens de significação. Assim, foram evidenciados os focos centrais à discussão e a identificação de aspectos mais recorrentes nas respostas.

\section{Resultados}

Este estudo buscou investigar como a expressão criativa é inserida no processo ensino-aprendizagem dos cursos técnicos de formação em dança. Para tanto, visando identificar se a expressão criativa se encontra inserida na formação desses sujeitos, foram analisadas as respostas dadas para as questões abertas pertinentes ao instrumento.

A proposta de Bardin (2011) prevê que a análise seja precedida pelo levantamento das unidades de significado e a categorização dessas variáveis. 
Dessa forma, para este estudo foram evidenciados indicadores significativos para análise, discussão e interpretação dos resultados, por meio dos Eixos Temáticos Principais:

\section{Eixo Temático 1 - Conceitos e significados da expressão criativa}

Este eixo visou a definição do que seria expressão criativa, a partir da percepção dos professores e bailarinos. Assim, por meio das respostas obtidas para a questão 'O que significa expressar-se criativamente?', pode-se perceber que a expressão criativa relaciona-se a uma forma própria e individual de expressão, conforme apresentado na tabela 1:

\section{Tabela 1 - Conceitos e significados da expressão criativa na dança}

\begin{tabular}{lcc}
\hline EXPRESSÃO CRIATIVA SIGNIFICA & PROFESSORES & BAILARINAS \\
\hline Movimentos com características individuais & 5 & 5 \\
Novidade/diferente & 2 & 3 \\
Liberdade & 5 & 2 \\
Expressão de sentimentos/emoções & 3 & 2 \\
Conexão com as músicas & 3 & 4 \\
Criar temas/coreografias/personagens & 2 & 3 \\
\hline
\end{tabular}

Os significados apontados pelos sujeitos evidenciam semelhanças com os apontamentos de Brown (2015), segundo os quais dançar envolve a expressão de ideias pessoais, o que possibilita promover o entendimento de novas perspectivas na dança. Tanto professores como estudantes demonstraram um entendimento de que a expressão criativa consiste em colocar no dançar suas próprias características, o que pode ser percebido também ao afirmarem a importância de ter liberdade para se expressarem. Ainda que os significados e conceitos da expressão criativa apresentem apontamentos diferenciados entre os sujeitos, percebe-se que o entendimento do que seria a expressão criativa na dança corrobora os conceitos apresentados na literatura da área, de acordo com os quais, ao ser criativo, o indivíduo expressa suas características pessoais.

Para Travi (2014), dançar pode se tornar um processo por meio do qual se podem expressar subjetividades, ou seja, de o indivíduo produzir seu modo de ser, de agir, de pensar, de se mover, revelando suas histórias, 
podendo significar um modo singular de se expressar. A autora destaca, ainda, os aspectos subjetivos na dança como matéria-prima para a criação, os quais, ao serem instigados, podem vir a ser um reflexo do sujeito, oferecendo maior autenticidade à manifestação artística.

Zachopoulou, Makri, e Pollatou (2009) ressaltam que a criatividade inclui a associação de diferentes processos e fatores individuais relacionados com o pensamento, a imaginação, a intuição, a motivação, entre outros. Entretanto, as ideias criativas são expressas a partir da percepção da utilidade, da administração das condições existentes, da afinidade e familiaridade com o ambiente. Sendo assim, a expressão na dança só será considerada criativa se o dançar for dotado de expressões significativas dos participantes, além de apresentar a novidade e o diferente. Esse conceito do novo também se apresentou nas respostas, tanto de professores como de bailarinas, e se refere à busca pelo diferente. A liberdade foi igualmente apontada, entre professores e bailarinos, como um evento relacionado à expressão criativa. Para Neves (2014), uma prática educativa de incentivo à criação instiga o aluno a utilizar sua liberdade de expressão e, dessa forma, tornar-se mais crítico, reflexivo e autónomo. Esses conceitos atribuídos à expressão criativa contribuem para a expressão do subjetivo e das individualidades, os quais se tornam recursos para construção de novas percepções e saberes.

Segundo Vygotski (2009), a criação envolve a expressão de esferas emocionais importantes. As emoções e os sentimentos se relacionam às vivências e se manifestam por meio de ideias, orientam os pensamentos, a imaginação e as ações corporais. Para Zachopoulou e Makri (2005), o ser humano expressa suas emoções por meio da criatividade. Silva e Schwartz (1999) evidenciam que a dança é uma prática permeada pelo desenvolvimento de potencialidades intrinsecamente ligadas à emoção, à expressão e à criatividade. As emoções e os sentimentos são, para Travi (2014), juntamente com as músicas, poemas e outros objetos, fontes para as criações coreográficas. Assim, a partir desses estímulos, pode-se intensificar a experiência do sensível, traduzindo o que há de singular naquele que dança. Entretanto, reconhecendo a importância do processo de ensinoaprendizagem, torna-se relevante considerar as orientações existentes nas práticas pedagógicas, capazes de encorajar esse envolvimento. Esses direcionamentos nortearam o eixo a seguir. 


\section{Eixo Temático 2 - Aspectos enfatizados no exercício da docência no âmbito dos cursos técnicos de formação em dança}

Este eixo objetivou identificar como a expressão criativa é enfatizada no processo de ensino e aprendizagem da dança. Entre os aspectos mais enfatizados em aula, as técnicas, juntamente com a expressividade, se mostraram elementos norteadores das práticas. A tabela a seguir mostra os aspectos mais realçados, de acordo com as respostas tanto dos professores como das bailarinas, e demonstra como e em que dimensão a expressão criativa é encorajada nas aulas.

\section{Tabela 2 - Aspectos enfatizados no exercício da docência nos cursos de formação em dança}

\begin{tabular}{lcc}
\hline ASPECTOS ENFATIZADOS NAS AULAS & PROFESSORES & BAILARINAS \\
\hline Técnicas específicas dos desempenhos & 9 & 8 \\
Esferas emocionais positivas & 7 & - \\
Expressividade & 6 & 7 \\
Atenção, disciplina, respeito e responsabilidade & 4 & 3 \\
Superação de limites & 1 & 1 \\
Realização pessoal/interação & 1 & - \\
Criatividade & - & 1 \\
Capacidades físicas e motoras & - & 2 \\
\hline
\end{tabular}

A ênfase dada às especificidades técnicas e à qualidade dos desempenhos foi comprovada nas respostas, tanto dos professores como das estudantes. Para Piccinini e Saraiva (2012), assim como para Souza (2011), o domínio da técnica, relacionado diretamente à aquisição de habilidades, se torna importante para a consciência das possibilidades motoras; porém, em um âmbito de arte-educação, deve ter a finalidade de potencializar, inclusive, a expressão, a comunicação, o prazer e a sensibilidade. Para tanto, Marques, Surdi, Assis, e Kunz (2014) salientam que o ensino das técnicas específicas da dança não deve ser centralizado em um aprender mecânico, limitado a ações reprodutivistas. Cabe ao docente promover a abertura para um aprender baseado no artístico e, ainda segundo esses autores, promover a experimentação, exploração e a reelaboração dos movimentos aprendidos.

Marques et al. (2014) salientam a importância de se estabelecer um diálogo entre as experiências de cada indivíduo e a aplicação das técnicas. Esta mesma perspectiva, referente à importância de se promoverem os 
fatores permeados pelas subjetividades e individualidades, também foi relevante para os participantes desse estudo, devendo, portanto, estar inseridos nas estratégias de ensino, no intuito de viabilizar uma aprendizagem mais significativa.

Entre os professores foram ressaltados aspectos referentes à ênfase dada ao incentivo a esferas emocionais positivas, relativas ao prazer de dançar e de sentir confiança. Entretanto, as respostas das estudantes não os confirmaram como aspectos que possam ter sido enfatizados no decorrer das aulas.

Neves (2014) destaca que, por meio dos movimentos aprendidos, além de novas emoções, o ser humano descobre novos comportamentos, o que se constitui em uma forma de linguagem e na construção de identidade. Esses significados podem ter sido contemplados nas respostas, tanto das bailarinas, como dos professores, pois ambos citaram a expressividade como um conteúdo enfatizado e relevante em suas práticas.

Segundo Marques et al. (2014), a criação ultrapassa a aprendizagem, trazendo novos sentidos e significados a uma vivência. Para tanto, a geração de um ambiente prazeroso e permeado pela sensibilidade e respeito ao outro pode interferir nas atividades e resultar no desenvolvimento de condutas mais criativas e expressivas. Contudo, a criatividade foi um aspecto citado por apenas uma bailarina, o que demonstra a necessidade de inserção de outras práticas diversificadas, incluindo um olhar reflexivo, em aula, sobre os significados dessa capacidade.

Aspectos como a superação de limites, a realização pessoal e a interação com o grupo também foram ressaltados. Quatro professores e três bailarinas salientaram fatores como concentração, disciplina, respeito e responsabilidade. Para duas bailarinas, existe uma ênfase dada ao desenvolvimento de capacidades físicas e motoras como força, flexibilidade e equilíbrio.

Do concluinte ou profissional Técnico em Dança é esperado que tenha desenvolvidas competências que lhe ofereçam condições para que atue como cidadão produtor, pesquisador do movimento e conhecedor dos elementos básicos da linguagem artística e estética da dança e dos princípios norteadores da educação profissional técnica (Ministério da Educação, 2014). 
Nesse sentido, cabe a esses cursos contribuir, não só para a formação técnica, mas também para a prática artística do futuro profissional de dança, conforme salientado por Corrêa e Nascimento (2013). Para tanto, as capacidades criativas e expressivas desenvolvidas se tornam conteúdos importantes, os quais são contemplados nas discussões a seguir.

\section{Eixo Temático 3 - Desenvolvimento da expressão criativa no âmbito dos cursos técnicos de formação em dança}

Este eixo visou analisar como a expressão criativa está inserida no âmbito didático-pedagógico. A esse respeito, os professores afirmaram que as atividades propostas envolvem a expressão criativa, o que foi confirmado nas respostas de todas as estudantes. Assim, no intuito de identificar como acontece o desenvolvimento da expressão criativa no contexto destes cursos técnicos de dança, uma questão abordou que atividades são propostas para tal finalidade. A tabela 3 apresenta os dados obtidos para essas respostas:

Tabela 3 - Desenvolvimento da expressão criativa nos cursos técnicos de formação em dança

\begin{tabular}{lcc}
\hline ATIVIDADES PROPOSTAS & PROFESSORES & BAILARINAS \\
\hline Coreografias & 8 & 5 \\
Movimentos e gestos livres & 6 & 3 \\
Brincadeiras e músicas & 6 & 4 \\
Criação de temas e histórias & 6 & 2 \\
Uso de figurinos e cenários & 2 & 1 \\
Interpretação de personagens & 2 & 2 \\
Espetáculos de dança & 2 & 3 \\
Interpretação e expressão de situações diversas & 2 & 6 \\
Exercícios de improvisação & 1 & 3 \\
Uso de desafios nas aulas & 1 & 7 \\
Pesquisas diversas & 1 & 1 \\
\hline
\end{tabular}

A possibilidade de criarem coreografias, diversificarem suas práticas e experimentarem novas expressões se tornam, assim, um processo importante no âmbito dessa formação. Essas associações são formas de se explorar diferentes linguagens e saberes, incluindo aqueles advindos das técnicas, de forma a proporcionar conexões entre os conteúdos aprendidos, com atribuição de sentidos a eles, o que corrobora os estudos de Corrêa e Nascimento (2013). Para estas autoras, essa conexão entre diferentes 
linguagens corresponde a uma forma de ler a dança e se relaciona com a interpretação e atribuição de sentidos para os códigos de dança. Essa leitura da dança pode ocorrer a partir de pesquisas sobre artistas ou outros, atividade citada por um dos professores e por uma bailarina. Já os movimentos e gestos livres, citados entre os professores e bailarinas, as coreografias, também citadas por ambos, assim como a criação de situações associadas ao uso de adereços e figurinos podem significar escrever a dança, para as autoras anteriormente citadas.

Entre as atividades propostas estão situações criadas a partir de temas ou de histórias, que podem ser indicados pelo professor ou de livre escolha do aluno e podem, inclusive, ser associados às tomadas de decisões - as quais, de acordo com Corrêa e Nascimento (2013), se referem à resolução de problemas, ou significam o uso de desafios, conforme proposto por um dos professores e reconhecido por sete das bailarinas. Assim, leitura e escrita da dança podem proporcionar a geração de novos saberes e ser contextualizadas como criações artísticas geradas a partir do que se aprendeu.

Entre os professores, as coreografias, as brincadeiras e as músicas foram associadas ao exercício da criatividade, o que foi confirmado nas respostas das bailarinas. As músicas são recursos que, para Correia (2010), podem atender aos propósitos de sensibilização, com possibilidades para estimular as expressões e a qualidade das performances. Quando associadas aos movimentos corporais e coreográficos, estes se tornam recursos para despertar facetas como emoção e criatividade. De igual modo, as brincadeiras foram enfatizadas no desenvolvimento da expressão da criatividade na dança, por este estudo. O brincar com os movimentos pode tornar a dança mais viva e prazerosa e favorecer a qualidade desta aprendizagem, ampliando o aprendizado de técnicas corporais.

Conforme Piccinini e Saraiva (2012), além de Sousa (2013), é na prática e na experimentação que o indivíduo descobre novas possibilidades de se movimentar. Dessa forma, o potencial criativo está associado ao coexistir do domínio das possibilidades expressivas e motoras. Assim, o movimento deve ser descoberto de forma a que o próprio corpo, motivado por estratégias pedagógicas, se torne uma possibilidade para se expressar e criar. As expressões criadas pelas estudantes, a partir da associação com 
diferentes temas, histórias, uso de metáforas, descrições verbais, interpretação de personagens, se mostraram determinantes na expressão das potencialidades criativas e foram percebidas, entre os professores, como estratégias pedagógicas capazes de trazer resultados artísticos importantes no desenvolvimento da expressão criativa. Estes aspectos foram ressaltados nas respostas das bailarinas.

Os exercícios de improvisação, de acordo com um dos professores, podem estar associados à geração de desafios nas aulas, o que foi confirmado nas respostas das bailarinas. Para Brasileiro e Marcassa (2008), Piccinini e Saraiva (2012) e Sousa (2013), as atividades que envolvem o improvisar são essenciais para o desenvolvimento de formas mais sensíveis e educativas de dançar. A ação de improvisar representa uma conduta capaz de transcender a transmissão de conhecimentos e possibilitar o uso do potencial criativo e expressivo; conduz, além da pesquisa de movimentos, à diversidade de pensamentos e à experimentação.

A organização curricular destes cursos técnicos prevê a realização de Festivais de Dança, espetáculos baseados em criações a partir de diferentes temas. Esses eventos mobilizam diferentes recursos para a expressão criativa e oferecem subsídios para enriquecer essa discussão, que foram evidenciados também nas respostas de dois professores e de três bailarinas. O processo de construção e elaboração desses festivais se mostrou uma oportunidade valiosa para o desenvolvimento artístico e pessoal na formação em dança. De acordo com as bailarinas, a oportunidade de interpretar um personagem significou experimentar diversas formas de se expressarem, sendo que essa atuação Ihes proporcionou prazer, bem-estar, a descoberta de novas capacidades e habilidades, além de ter promovido maior interação entre a turma. Essa foi vista, portanto, como uma oportunidade rica para novas aprendizagens, tanto durante as experimentações em sala de aula, como no decorrer do espetáculo. Nessa perspectiva, a gama de conhecimentos e práticas utilizados em um espetáculo de dança é permeada por um fazer artístico que é instigado pela exploração de novas habilidades. Para tanto, as músicas, os figurinos e cenários diversificados, os recursos de iluminação, o desenvolvimento de temas, de sequências coreográficas e da interpretação dos personagens, todos esses, compondo um todo coeso, podem fomentar um processo de criação na dança, o que, conforme Sousa (2013), ocorre a partir da experimentação. 


\section{Considerações finais}

Os dados obtidos e analisados por meio dos Eixos Temáticos permitiram identificar algumas das interfaces de entendimento entre os professores e as estudantes acerca da inserção da expressão criativa na dança. A expressão criativa é vista por ambos, professores e bailarinas, como uma possibilidade de colocarem nos movimentos suas próprias características, suas percepções, suas emoções, e de terem liberdade para se expressar.

A expressão criativa acontece em meio a um processo, em que o produto criativo, na dança, passa a ser percebido a partir das vivências práticas como uma forma de expressão. Quanto ao modo como a expressão criativa está inserida no âmbito dos cursos técnicos de formação em dança, para os sujeitos desta pesquisa, ela se apresenta de forma essencialmente subjetiva e acontece de maneira esparsa, por meio da ênfase dada aos aspectos emocionais, ao estímulo na superação de desafios e à possibilidade de inserirem características próprias no movimento, valorizando as individualidades.

Apesar de as técnicas terem sido apontadas como os aspectos mais enfatizados no exercício da docência, as estudantes percebem a inserção de um repertório de atividades facilitador para a expressão. Também foi percebido que a expressão criativa se apresentou de modo significativo, ainda que isso tenha sido descrito de forma esparsa. No contexto destes cursos, foram citados pelas bailarinas diferentes momentos e formas de inserção destes conteúdos. Vale ainda ressaltar que, além das aulas, os espetáculos de dança são considerados um espaço aberto para o desenvolvimento da expressão criativa.

As atividades descritas como propostas para a inserção da expressão criativa estiveram permeadas por elementos como coreografias, músicas, criação de temas e histórias, uso de figurinos e cenários, interpretação de personagens, desafios e pesquisa. Estes representam recursos utilizados para ler e escrever a dança e para a resolução de problemas, conforme salientado por Corrêa e Nascimento (2013). A associação entre esses apontamentos é o que compõe o fazer artístico e fomenta o que este estudo entende como expressão criativa: uma forma de criação em que o dançar é 
aliado a uma forma de expressão, na qual o indivíduo demonstra sua criatividade, por meio de gestos e movimentos baseados no novo e no que for significativo aos contextos individuais, emocionais e sociais. Todavia, consoante os pressupostos recomendados para essa formação técnica, torna-se premente a adoção de estratégias pedagógicas, no intuito de tornar essas vivências com a expressão criativa um recurso pontual no cotidiano dessa formação.

Os dados recolhidos evidenciam diversos aspectos ainda obscuros a serem pesquisados no universo da formação em dança. Para tanto, outros estudos são necessários, no sentido de se apreender a complexidade das relações expressivas, criativas e subjetivas focalizadas especificamente no ensino da arte de dançar, em seus significados, nos currículos e objetivos de outros cursos técnicos, além de outros contextos referentes à atuação dos profissionais ligados à dança.

\section{Referências}

Bardin, L. (2011). Análise de conteúdo (ed. revisada e ampliada). Lisboa: Edições 70.

Bastos, F., \& Zimmerman, E. (2015). Connecting creativity research and practice in art education: Foundations, pedagogies, and contemporary issues. Reston, VA: National Art Education Association.

Brasileiro, L. T., \& Marcassa, L. P. (2008). Linguagens do corpo: Dimensões expressivas e possibilidades educativas da ginástica e da dança. Pro-Posições, 19(3), 195207.

Brown, A. K. (2015). Dance education: Embodied knowing in the digitalised world. In C. S. Nielsen \& S. Burridge (Eds.), Dance education around the world: Perspectives on dance, young people and change (pp. 141-148). Oxon: Routledge.

Corrêa, J. F., \& Nascimento, F. M. (2013). Ensino de dança no Rio Grande do Sul: Um breve panorama. ConceiçãolConception, 1(3), 53-68. Disponível em: http://www.publionline.iar.unicamp.br/ index.php/ppgac/article/view/154/162.

Correia, M. A. (2010). A função didático-pedagógica da linguagem musical: Uma possibilidade na educação. Educar em Revista, 1(36), 127-145.

Csikszentmihalyi, M. (2013). The psychology of discovery and invention. New York: Harper Perennial Modern Classics.

Csikszentmihalyi, M., \& Wolfe, R. (2014). New conceptions and research approaches to creativity: Implications of a systems perspective for creativity in education. In M. Csikszentmihalyi, The systems model of creativity (pp. 161-184). New York: Springer. 
Hetland, L., Winner, E., Veenema, S., \& Sheridan, K. M. (2013). Studio thinking: The real benefits of visual arts education. Hetland: Teachers College Press.

Lopes, S. S. (2009). Para além das técnicas: Estratégias pedagógicas de 3 professoras de dança ou a presença como modo de estar ali (Dissertação de mestrado). Porto Alegre-RS-Brasil, Universidade Federal do Rio Grande do Sul, Faculdade de Educação.

Lubart, T. (2007). Psicologia da criatividade. Porto Alegre: Artmed.

Marques, D. A. P. (2012). O "se-movimentar" na dança: Uma abertura para novas significações - Diálogos na educação (Dissertação de mestrado). FlorianópolisSanta Catarina-Brasil, Universidade Federal de Santa Catarina, Centro de Desportos.

Marques, D. A. P., Surdi, A. C., Assis, M. D. P., \& Kunz, E. (2014). Das técnicas específicas e do mundo vivido: Implicações sobre o imitar e o criar na dança. Pensar a Prática, 17(3), 849-864. doi: 10.5216/rpp.v17i3.26903

Marques, D. A. P., Surdi, A. C., Grunennvaldt, J. T., \& Kunz, E. (2013). Dança e expressividade: Uma aproximação com a fenomenologia. Movimento, 19(1), 243-263.

Medina, J., Ruiz, M., Almeida, D. B. L., Yamaguchi, A., \& Marchi Jr., W. (2008). As representações da dança: Uma análise sociológica. Movimento, 14(2), 99-113.

Ministério da Educação (2014). Catálogo Nacional de Cursos Técnicos: Edição 2014. Brasília: Secretaria de Educação Profissional e Tecnológica. Disponível em: http://sistemas.wiki.ifpr.edu.br/lib/exe/fetch.php?media=catalogo_2014.pdf

Neves, A. M. (2014). Dança e psicomotricidade: Propostas do ensino da dança na escola. Scias - Arte/Educação, 3(3), 67-85. Disponível em: http://www.uemg.br/ openjournal/index.php/SCIAS/article/view/577/pdf

Piccinini, L., \& Saraiva, M. C. (2012). A dança-improvisação e o corpo vivido: Ressignificando a corporeidade na escola. Pensar a Prática, 15(3), 551-820. doi: 10.5216/rpp.v15i3.14532

Sawyer, R. K. (2012). Explaining creativity: The science of human innovation (2. ${ }^{\mathrm{a}}$ ed.). New York: Oxford University Press.

Silva, M. G. M. S., \& Schwartz, G. M. (1999). A expressividade na dança: Visão do profissional. Motriz, 5(2), 168-177.

Sousa, P. H. A. (2013). Dança contemporânea: Percepção, contradição e aproximação. Pensar a Prática, 16(4), 1014-1030. doi: 10.5216/rpp.v16i4.20245.

Souza, M. I. G. (2011). O ensino da dança: Técnica ou criatividade. Cadernos de Formação, RBCE, 2(1), 32-42.

Sternberg, R. J. (2012). The assessment of creativity: An investment-based approach. Creativity Research Journal, 24(1), 3-12. doi: 10.1080/10400419.2012.652925

Sternberg, R. J., \& Lubart, T. I. (1999). The concept of creativity: Prospects and paradigms. In R. J. Sternberg (Ed.), Handbook of creativity (pp. 3-16). Cambridge: Cambridge University Press.

Travi, M. T. F. (2014). Caminhos para dançar-se: Elementos da psicanálise no processo criativo de Pina Bausch (Dissertação de mestrado). Porto Alegre-RS-Brasil, Universidade Federal do Rio Grande do Sul, Instituto de Artes. 
Vygotski, L. (2009). A imaginação e a arte na infância. Lisboa: Relógio D’Água.

Winner, E., Goldstein, T. R., \& Vincent-Lancrin, S. (2014). Does arts education foster creativity? The evidence so far. In L. O Farrell, S. Schonmann, \& E. Wagner (Eds.), International yearbook for research in arts education (vol. 2, pp. 95-100). Münster: Waxmann Verlag.

Wyrick, W. (1968). The development of a test of motor creativity. Research Quarterly, 39(3), 756-765. doi: 10.1080/10671188.1968.10616608

Zachopoulou, E., \& Makri, A. (2005). A developmental perspective of divergent movement ability in early young children. Early Child Development and Care, 175(1), 85-95. doi: 10.1080/0300443042000230401

Zachopoulou, E., Makri, A., \& Pollatou, E. (2009). Evaluation of children's creativity: Psychometric properties of Torrance's 'Thinking Creatively in Action and Movement' test. Early Child Development and Care, 179(3), 317-328. doi:10.1080/03004430601078669

Zimmerman, E. (2013). Presences and absences: A critical analysis of recent research about creativity in visual arts education. In K. Thomas \& J. Chan (Eds.), Handbook of research on creativity (pp. 48-65). UK: Edward Elgar Publishing.

\section{Legislação}

Decreto 5.154/2004, de 23 de julho de 2004. Regulamenta o $\S 2^{\circ}$ do art. 36 e os arts. 39 a 41 da Lei $n^{\circ}$ 9.394, de 20 de dezembro de 1996, que estabelece as diretrizes e bases da educação nacional, e dá outras providências. Diário Oficial da União, Brasília, 26 jul. 2004, seção 1, p. 18. 


\title{
EDUCATION AND TRAINING IN DANCE: THE INCLUSION OF CREATIVE EXPRESSION IN THE TECHNICAL DANCE COURSES FROM THE PERSPECTIVE OF TEACHERS AND DANCERS
}

\begin{abstract}
This qualitative study aimed to investigate how the creative expression is included in the teaching and learning process of dance in technical courses from the viewpoint of dancers and teachers. This exploratory research was conducted by open questionnaire applied to an intentional sample composed by 10 teachers and 10 dancers enrolled in the technical courses of dance of Pirassununga-SP-Brazil. Data were descriptively analyzed, using the Content Analysis Technique. Results indicate that although creative expression is perceived as an effective way for making art and is emphasized for the didactic-pedagogic work, its inclusion is minimized in the educational context of dance, contrary to what happens with the technical aspects. Its development involves subjective aspects during the classes and it appears sparsely. Other studies are necessary in order to resize and revitalize this topic in the academic context.
\end{abstract}

Keywords

Dance; Creativity; Vocational training; Education

\section{LA EDUCACIÓN Y LA FORMACIÓN EN LA DANZA: LA INSERCIÓN DE LA EXPRESIÓN CREATIVA EN LOS CURSOS TÉCNICOS DE DANZA EN LA PERSPECTIVA DE LOS PROFESORES Y BAILARINES}

Resumen

Este estudio cualitativo investigó como la expresión creativa se insiere en la enseñanza y el aprendizaje de los cursos de capacitación técnica en la danza, en la visión de bailarines y profesores. Esta investigación exploratoria se realizó mediante un cuestionario abierto administrado a una muestra 
intencional de 10 profesores y 10 bailarines de cursos de capacitación técnica en la danza de Pirassununga-SP-Brasil. Los datos fueron analizados descriptivamente, utilizando la Técnica de Análisis del Contenido. Los resultados indican que, a pesar de la expresión creativa ser ampliamente percibida como relevante en la apropiación de la leyenda de la obra artística y se acentuar para el trabajo didáctico-pedagógico, su inclusión es minimizada en el contexto educativo de la danza, en contraposición a la valoración dada a los aspectos técnicos. Su desarrollo está permeado por aspectos subjetivos durante las clases y se presenta escasamente. Son necesarios otros estudios para redimensionar y revitalizar este tema en el ámbito académico.

Palabras-clave

Danza; Creatividad; Formación profesional; Educación

Recebido em julho/2015

Aceite para publicação em fevereiro/2016

i Laboratório de Estudos do Lazer, Instituto de Biociências, Departamento de Educação Física, Universidade Estadual Paulista, Brasil.

ii Laboratório de Estudos do Lazer, Instituto de Biociências, Departamento de Educação Física, Universidade Estadual Paulista, Brasil.

iii Laboratório de Estudos do Lazer, Instituto de Biociências, Departamento de Educação Física, Universidade Estadual Paulista, Brasil.

iv Laboratório de Estudos do Lazer, Instituto de Biociências, Departamento de Educação Física, Universidade Estadual Paulista, Brasil.

Toda a correspondência relativa a este artigo deve ser enviada para: Priscila Trevisan, Rua Natal, $\mathrm{n}$. 2068, Vila Belmiro, CEP 13.633-508, Pirassununga, São Paulo - Brasil. E-mail: priscilalel28@gmail.com 